\section{CRISP, CLEAR, HIGH-CONTRAST IMAGES}

A dental operating microscope (DOM) can prove a powerful addition to any modern dental practice, and can greatly enhance the level of care a practice team can provide. When seeking to invest in a DOM, managers should ensure they choose a brand that offers superior quality, and a supplier that can provide comprehensive and knowledgeable support.

With over 150 years' experience in the field of

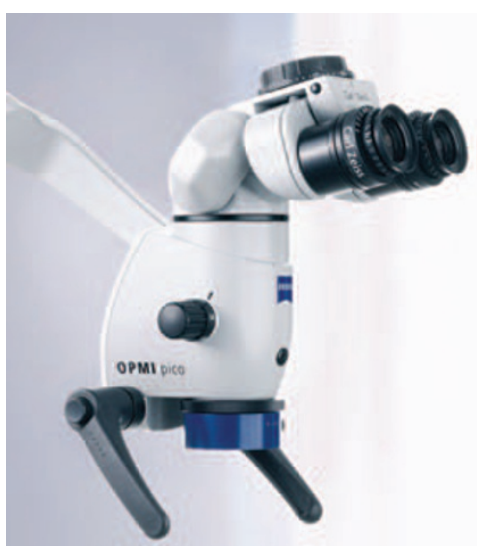

precision mechanics and optics, Carl Zeiss has long been established as one of the world's leading names in magnification and illumination systems. Available exclusively from Nuview in the UK, Carl Zeiss microscopes feature the latest in integrated ergonomic design, and produce crisp, clear, high-contrast images for perfect visualisation. To further enhance your system, Carl Zeiss microscopes can be upgraded with HD video or stills recording equipment that can prove a great educational tool and can also enhance the process of obtaining treatment consent.

To learn more about how your practice can benefit from an exceptional Carl Zeiss dental operating microscope, contact the team at Nuview today on 01453872266 or email info@ nuview-ltd.com.

\title{
CLEAN INSTRUMENTS IN JUST 12 MINUTES
}

When you buy Sirona Equipment from Sident Dental Systems you not only get the best price and exclusive special offers, but you also get access to the best sales support in the UK. This includes the DAC Universal, which Sident Dental Systems believe is the ideal handpiece autoclave. Fully automatic, it eliminates errors and frees staff for other tasks.

In just 12 minutes, the DAC Universal enables practices to clean, lubricate and sterilise up to six turbines, straight or contra-angled handpieces from any manufacturer at the touch of a button.

First any debris or biofilm is removed, quickly and safely, even from the internal channels of contra-angled handpieces which are normally difficult to clean manually.
Then automatic lubrication with a measured amount of oil takes place. Finally, one of three sterilisation programmes is activated according to Sirona's proven back-flush principle - leaving the handpieces ready for use.

Using just two steps, cold cleaning (pulse wash) and hot cleaning, the DAC Universal helps reduce repairs and extends the working life of handpieces. With various safety features - including a sensor which accurately determines water quality and an optional printer which documents the time, temperature, serial number and sterilisation cycle - it is approved by all the main handpiece manufacturers.

For further information call 01932582900 or email j.colville@sident.co.uk.

\section{OPTIMAL FUNCTIONALITY AND COMFORT}

Working in partnership with the highly experienced RPA Dental, Tavom design and create new dental practices beyond all expectations. The different product ranges from Tavom, available in a range of materials and colours, are customised to cater to the needs of all areas of the practice, from the reception area to surgery rooms.

Innovative storage solutions also allow you to maximise the use of the space available, ensuring optimal functionality while promoting a comfortable and relaxing atmosphere.

For quality-conscious professionals who are looking for a new practice design, look no further than Tavom.

For more information call Tavom UK on 08707521121 or visit the Tavom website www. tavomuk.com.

\section{END OF AN ERA FOR HISTORIC PRACTICES}

Growing legislative pressure will soon see an end to period houses being used as dental practices, predicts Roger Gullidge of Roger Gullidge Design.

The demands of legislation including HTM 01-05 and the Disability Discrimination Act are incompatible with the challenges of seeking Listed Building Consent, Conservation Area Consent and Planning Permission.

According to Roger, if you apply for Listed Building Consent to divide up rooms in a classic Georgian or Victorian Terrace to fit in a Local Decontamination Unit, you are unlikely to succeed. The whole process becomes unviable and you will essentially be compelled to move.

The ability to extend and modify newer buildings, and the reduced complexity involved in connecting them to modern communications networks, makes them far more practical locations for dental practices. The wider availability of parking spaces and improved disabled access can also make them more appealing to patients.

Roger Gullidge Design is a design and project management consultancy specialising in the dental sector. Call 01278784442 for more details or visit www.rogergullidgedesign.com.
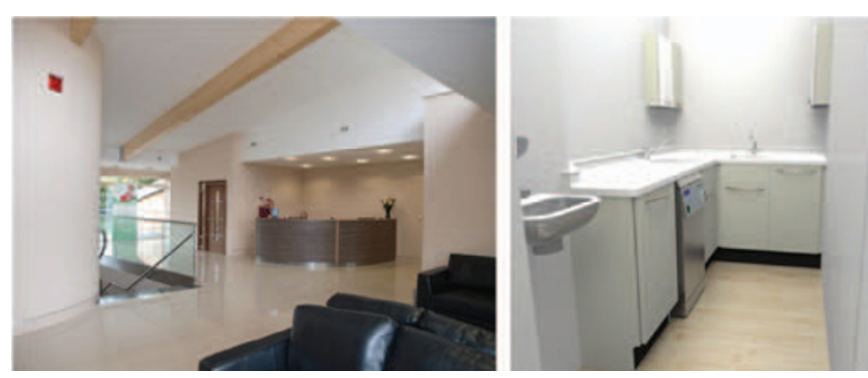